\title{
AVALIAÇÃO TEMPORAL DA FREQUÊNCIA DA INFECÇÃO DO HIV EM
}

GESTANTES

\author{
TEMPORAL EVALUATION OF FREQUENCY OF HIV INFECTION IN \\ PREGNANT WOMEN
}

\author{
Juliana Barroso Zimmermmann ${ }^{1}$, \\ Adrianne Maria Berno de Rezende Duarte ${ }^{1}$, \\ Alexander Cangussu Silva ${ }^{1}$
}

Clin Biomed Res. 2017;37(3):198-202

1 Faculdade de Medicina, Universidade Federal de Juiz de Fora (UFJF). Juiz de Fora, MG, Brasil.

Autor correspondente: Juliana Barroso Zimmermmann julianabz@uol.com.br Departamento Materno Infantil, Faculdade de Medicina, Universidade Federal de Juiz de Fora (UFJF) Rua José Lourenço Kelmer. 36036-330, Juiz de Fora, MG, Brasil.

\section{RESUMO}

Com a evolução da epidemia de AIDS nas últimas décadas, houve um aumento expressivo do número de casos entre heterossexuais. A feminização da epidemia acelerou a disseminação geográfica do vírus da imunodeficiência humana (HIV) em todo o território nacional, determinando também o aumento de crianças infectadas pela transmissão materno-infantil. A frequência da infecção pelo HIV em gestantes atendidas pelo Serviço de Obstetrícia da Universidade Federal de Juiz de Fora, nos períodos de 2009-2015 (grupo 1) foi avaliada e comparada com a frequência da infecção pelo HIV no mesmo serviço no período de 1998-2002 (grupo 2). A comparação dos dados revelou uma menor frequência da infecção pelo HIV no grupo 1. Os autores identificaram queda da frequência da infecção pelo HIV ao longo do tempo, com estabilização nos últimos anos.

Palavras-chave: Infecção pelo HIV; gravidez; cuidado pré-natal

\section{ABSTRACT}

There has been a significant increase in the number of cases of AIDS among heterosexuals, due to the dissemination of AIDS epidemic in recent decades. The feminization of the epidemic accelerated the geographical spread of the human immunodeficiency virus (HIV) throughout the Brazilian territory and also led to an increase of children infected by mother-child transmission. The frequency of HIV infection in pregnant women attending the Obstetrics Service of Federal University of Juiz de Fora was evaluated from 2009-2015 (group 1) was evaluated and compared with the frequency of HIV infection in the same department from 1998-2002 (group 2). Intergroup comparison revealed a decrease in the frequency of HIV infection in group 1. The authors found a decrease the frequency of HIV infection, with stabilization in recent years.

Keywords: HIV infection; pregnancy; prenatal care

Com a evolução da epidemia de AIDS nas últimas décadas, houve um aumento expressivo do número de casos entre heterossexuais. A feminização da epidemia acelerou a disseminação geográfica do vírus da imunodeficiência humana (HIV) em todo o território nacional, ocasionando também o aumento no número de crianças infectadas pela transmissão materno-infantil (TMI) ${ }^{1,2}$. A TMI pode acontecer na gestação, no parto e também na amamentação, mas $65 \%$ dos casos ocorrem no parto, e a carga viral materna é um fator de risco determinante na transmissão ${ }^{3,4}$. Por isso, o rastreio da infecção pelo HIV é fundamental no pré-natal, sendo considerado exame obrigatório na propedêutica habitual ${ }^{5}$.

O Departamento de DST, AIDS e Hepatites Virais estimou que 734.000 pessoas viviam com HIVIAIDS no Brasil em 2014. No período de 2000 até junho de 2016, foram notificadas 99.804 gestantes infectadas com HIV. Verificou-se que $39,8 \%$ das gestantes residiam na Região Sudeste $(39,8 \%)$, seguida pelas 
Regiões Sul $(30,8 \%)$, Nordeste $(16,2 \%)$, Norte $(7,4 \%)$ e Centro-Oeste $(5,7 \%)^{6}$. A taxa de detecção de gestantes com HIV no Brasil vem apresentando tendência de aumento nos últimos 10 anos. Em 2006, a taxa observada foi de 2,1 casos/1.000 nascidos vivos, a qual passou para 2,7 em 2015, indicando um aumento de $28,6 \%$. A capital do estado de Minas Gerais, Belo Horizonte, apresentou taxa de detecção inferior à média nacional, compatível com a da Região Sudeste, que vem apresentando queda nos últimos anos ${ }^{6,7}$. Por outro lado, Porto Alegre é a capital com a maior taxa de deteç̧ão em 2015, com 22,9 casos para cada 1,000 nascidos vivos, sendo 8,4 vezes maior que a taxa nacional e o dobro da taxa do seu estado 6 .

O Serviço de Obstetrícia da Faculdade de Medicina da Universidade Federal de Juiz de Fora (UFJF) presta atendimento à população da cidade e região e, portanto, o conhecimento das taxas em nosso serviço e de seu comportamento em relação à média nacional e regional é fundamental para o estabelecimento de políticas públicas de saúde voltadas especialmente para as mulheres e seus recém-nascidos. Baseado no exposto, nos propomos a avaliar a prevalência da infecção pelo HIV em nosso serviço entre 2009 e 2015 e compará-la com obtida em um estudo realizado no mesmo local entre 1998 e 2002.

\section{MÉTODOS}

Foi realizado um estudo transversal, com comparação entre grupos, através da avaliação de 4.577 prontuários de gestantes atendidas pelo Serviço de Obstetrícia da Faculdade de Medicina da UFJF no período de janeiro de 2009 a dezembro de 2015 (grupo 1).

Para a comparação (grupo 2) utilizaram-se dados de um estudo realizado no mesmo serviço no período de 1998 a 2002, quando se verificou a frequência isolada e estratificada da infecção pelo HIV em gestantes. Naquela época, testaram-se 1.236 gestantes, identificando-se 13 gestantes soropositivas para o HIV, com as seguintes incidências anuais: 0,005 (0,5\%) em 1998, 0,002 (0,2\%) em 1999, 0,02 (2\%) em 2000, 0,01 (1\%) em 2001 e 0,04 (4\%) em janeiro e fevereiro de $2002^{3}$.

A comparação entre os dois momentos foi possível devido ao fato de a avaliação das pacientes ter sido realizada pela mesma equipe, ter sido utilizado um prontuário padrão, e a propedêutica obstétrica ter sido realizada conforme orientações da Federação Brasileira de Ginecologia e Obstetrícia (FEBRASGO) ${ }^{8}$. As pacientes foram submetidas a anamnese e exame físico obstétrico, quando foi solicitada a propedêutica habitual de pré-natal. Essas pacientes foram orientadas sobre a importância do rastreio para a infecção HIV durante o pré-natal e concordaram em realizar o exame, com aconselhamento antes e após o teste, conforme prontuário.

O rastreio da infecção pelo HIV foi realizado em duas etapas, conforme preconizado pelo Ministério da Saúde. Inicialmente, utilizou-se o teste ELISA e, para a confirmação diagnóstica, o teste Western Blot ${ }^{9}$. Todas as pacientes foram também acompanhadas pelo Serviço de Infectologia da UFJF/Prefeitura Municipal de Juiz de Fora.

Foram solicitados pelo menos dois testes anti-HIV para cada paciente, sendo um no primeiro e outro no terceiro trimestres. Importante ressaltar que alguns dos resultados não ficaram prontos em tempo hábil, considerando o parto. Nesse caso, a partir de 2009, essas pacientes foram submetidas ao teste rápido durante sua internação, depois complementado com teste convencional. Esses resultados não foram considerados no estudo. Todas as pacientes receberem aconselhamento pré e pós-teste objetivando o acolhimento, a orientação e a ampliação do senso de responsabilidade necessária à prevenção da infecção pelo vírus HIV 10,11.

Os dados dos prontuários foram transcritos em uma planilha confeccionada em Excel v. 8.0. A seguir, os dados foram exportados para o programa Epi Info v. 6.0.4. A comparação entre os grupos foi realizada através da análise da variância (ANOVA), considerado como nível de significância $p<0,05$. A comparação entre as frequências foi realizada através da razão de prevalência. Este estudo faz parte do projeto de pesquisa aprovado pelo CEP-FHEMIG sob o parecer 1.765.348.

\section{RESULTADOS}

No período de janeiro de 2009 e dezembro de 2015 , foram registradas no cadastro de gestantes da Faculdade de Medicina da UFJF 4.577 pacientes. $O$ cadastro foi realizado no dia da primeira consulta pré-natal, quando foram solicitados os exames de rotina pré-natal, inclusive o anti-HIV. Obteve-se retorno de 3.623 pacientes; destas, 3.435 (94,8\%) tiveram exames com resultado negativos, 162 (4,5\%) não tinham realizado o exame até aquele momento, e $26(0,7 \%)$ apresentaram resultado positivo, o que determinou uma frequência acumulada no período de $0,7 \%$.

A partir de 2009 , a quase totalidade das pacientes foi rastreada com dois testes $(99,2 \%)$. Houve apenas um único caso de paciente soronegativa no primeiro exame (consulta inicial) com conversão sorológica na repetição do exame. A partir de 2015, iniciamos os 
testes trimestrais para rastreio da infecção pelo HIV. Não houve nenhum caso de infecção de recém-nascido relatado a partir de 2009. Anteriormente, os dados não foram totalmente recuperados porque os prontuários não eram digitalizados.

A estratificação anual foi também realizada e está descrita na Tabela 1 e na Figura 1. No grupo 1, identificaram-se 13 casos de gestantes soropositivas para o HIV em um total de 1.236 exames realizados, o que determinou uma frequência acumulada no período de 0,01 . No grupo 2, identificaram-se 26 gestantes soropositivas para o HIV em um total de 3.626 exames, determinando frequência acumulada no período de 0,007.

Amédia de idade das pacientes soropositivas do grupo 1 foi de $26,14 \pm 7,23$ anos, com variação de 14 a 49 anos, e de $28,33 \pm 8,2$ anos no grupo 2. Quando se comparou as médias identificou-se $p<0,05$, de forma que as gestantes do grupo 1 são mais jovens quando comparadas com as do grupo 2 .

\section{DISCUSSÃO}

Ao longo dos anos, houve modificação em relação ao rastreio para a infecção pelo HIV em nosso serviço. No passado, um único teste era oferecido à gestante, na primeira consulta pré-natal. Com o passar dos anos e atendendo às novas diretrizes do Ministério da Saúde, dois testes de rastreio passaram a ser realizados. A partir de 2009 , tivemos um caso de paciente com conversão sorológica durante o pré-natal. A repetição do exame no terceiro trimestre foi importante porque permitiu a introdução de medidas profiláticas para o recém-nascido visando o controle da doença materna. Atualmente, fazemos os testes de rastreio trimestrais. Essa conduta foi iniciada no final de 2015. A grande vantagem da repetição do teste é redução dos falsos negativos, especialmente por causa da janela imunológica, de forma que hoje ainda realizamos o teste rápido na maternidade, a fim de permitir a profilaxia durante o trabalho de parto e do recém-nascido ${ }^{12}$.

Tabela 1: Apresentação da incidência da infecção pelo HIV em gestantes de acordo com o período proposto.

\begin{tabular}{ccccc}
\hline Ano & Gestantes HIV (+) & Gestantes HIV (-) & Total de exames & Incidência \\
\hline 1998 & 2 & 368 & 370 & 0,0054 \\
1999 & 1 & 359 & 360 & 0,0027 \\
2000 & 6 & 282 & 288 & 0,0208 \\
2001 & 3 & 194 & 197 & 0,0154 \\
2002 & 1 & 20 & 21 & 0,0476 \\
2009 & 7 & 485 & 540 & 0,0144 \\
2010 & 3 & 531 & 557 & 0,0056 \\
2011 & 2 & 532 & 571 & 0,0037 \\
2012 & 2 & 452 & 469 & 0,0044 \\
2013 & 5 & 454 & 479 & 0,0110 \\
2014 & 4 & 536 & 0,0076 \\
2015 & 3 & 461 & 474 & 0,0065 \\
\hline
\end{tabular}

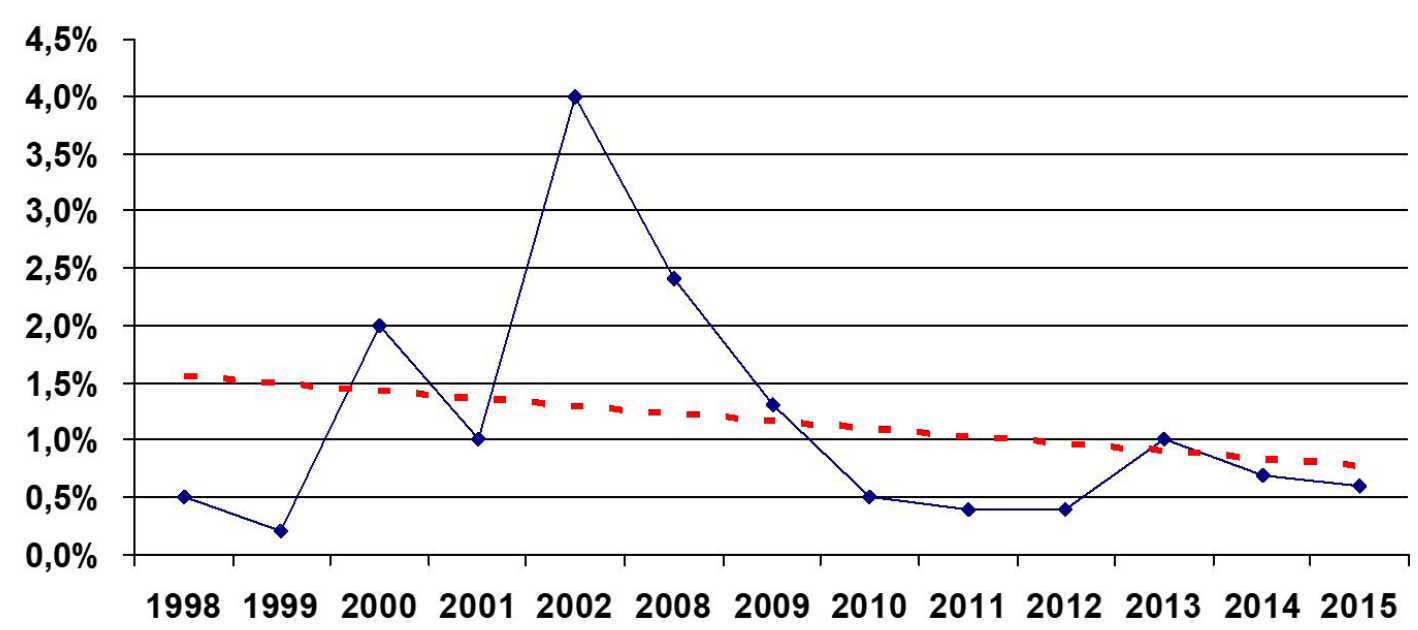

Figura 1: Frequência da infecção pelo HIV em gestantes nos períodos de 1998-2002 e 2008-2015. Em pontilhado tem-se a linha de tendência do gráfico. 
A taxa de transmissão vertical do HIV sem qualquer intervenção se situa em torno de $20 \%$. Com o uso combinado das intervenções habituais, pode-se reduzir a TMI para cifras menores que $1 \%$. Apesar das dificuldades que os serviços públicos atravessam, seja na realização do teste anti-HIV, na assistência pré-natal e até na distribuição das formulações lácteas para o recém-nascido, a incidência de casos de AIDS em crianças vem decrescendo progressivamente no pais ${ }^{7,12,14}$. Nesse contexto, não se pode deixar de citar que a redução da infecção em gestantes tem efeito modulador na taxa de transmissão materno-fetal. Em nosso serviço, a partir de 2009 não foram identificados casos de transmissão materno-fetal, o que está de acordo com a estabilização das taxas de detecção de HIV em gestantes. Em relação ao período anterior, os dados não puderam ser completamente avaliados, já que naquela época os prontuários não eram informatizados.

Quando se avaliou a idade dessas pacientes, nosso estudo verificou que houve redução da idade ao longo dos anos, de forma que as pacientes com diagnóstico da infecção pelo HIV do período mais recente (2009-2015) são mais jovens, quando comparadas com as do período anterior (1998-2002). Segundo o Boletim Epidemiológico do Ministério da Saúde, desde 2000 a faixa etária entre 25 a 29 anos é a que apresenta o maior número de casos de gestantes infectadas pelo HIV com notificação no Sistema de Informação de Agravos de Notificação (SINAN). Esse é um problema que não parece se resolver a longo prazo, já que uma grande preocupação tem sido a infecção feminina na faixa etária de 13 a 19 anos. Essas meninas infectadas provocariam uma piora da epidemia de AIDS no Brasil, principalmente devido ao perigo de um aumento da transmissão vertical do vírus. Acredita-se que o início precoce da atividade sexual, normalmente com homens com maior experiência sexual e mais expostos aos riscos de contaminação por DST, seja um fator determinante da infecção nessa faixa etária mais jovem. Dessa forma, pode-se supor que mais jovens estão vivendo com HIVIAIDS e que uma parcela considerável desses pacientes contraiu o vírus na adolescência ${ }^{12,14}$. Essa tendência reduzirá a média de idade das mulheres grávidas soropositivas.

Quando se comparou a frequência de gestantes soropositivas nos dois momentos, verificou-se uma tendência à estabilização nos últimos anos. Entretanto, no Brasil a frequência da infecção pelo HIV em gestantes vem mostrando crescimento. Por outro lado, a única região que permaneceu estável foi a Sudeste, que manteve taxa de 2,2 e 2,1 casos/1.000 nascidos vivos em 2006 e 2015, respectivamente. Apesar de a Região Sudeste ter a maior concentração de casos de AIDS no Brasil $(53,8 \%)$, é a única região que apresentou queda nas taxas de detecção $(26,5 \%)$ nos últimos 10 anos. As possíveis explicações para essa estabilização podem estar associadas ao maior desenvolvimento da região e à facilidade de acesso aos centros de atendimento, permitindo cuidado continuado após o diagnóstico, de forma que esses dados refletem desigualdades e vulnerabilidades sociais , $^{73-15}$. Pode-se então supor que a AIDS é um potente marcador social. O presente estudo foi desenvolvido na cidade de Juiz de Fora, estado de Minas Gerais, e a frequência de infeção pelo HIV em gestantes acompanhou a da região na qual estamos inseridos. Dado importante é que nosso serviço não apresentou alta frequência de gestantes HIV soropositivas diagnosticadas no pré-natal, quando comparado com os serviços de outros grandes centros. Entretanto, essa frequência não reflete o número total de pacientes soropositivas atendidas em regime de pré-natal. As gestantes sabidamente soropositivas são acompanhadas no serviço de alto risco obstétrico e não são submetidas a exames de rastreio para o HIV, por já terem diagnóstico prévio. Dados do SINAN identificaram 502 gestantes infectadas pelo HIV no período de 2003 a 2015, sendo que em 2014 foram diagnosticados 38 casos e nosso serviço rastreou $10 \%$ dessas gestantes ${ }^{16}$.

Desse modo, concluímos que houve estabilização da frequência da infecção nos últimos anos e uma redução da idade média das gestantes com infecção pelo HIV quando comparada com a do período anterior.

\section{REFERÊNCIAS}

1. Silva LCF, Santos EM, Silva AL No, Miranda AE, Talhari S, Toledo LM. Padrão da infecção pelo HIV/ AIDS em Manaus, Estado do Amazonas, no período de 1986 a 2000. Rev Soc Bras Med Trop. 2009;42(5):543-50. PMid:19967237. http://dx.doi.org/10.1590/S003786822009000500012 .
2. Zimmermmann JB, Neves HS, Souza PB, Pena DM, Pereira MP, Nunes $T R$, et al. Screening of infection by human immunodeficiency virus at the time of delivery. Rev Bras Ginecol Obstet. 2011;33(4):170-5. PMid:21845348.

3. Araujo DAC, Zimmermmann JB, Vieira LHC, Vieira CM, Oliveira L, Gama AL, et al. O rastreio sorológico para HIV em gestantes. Bol Cent Biol Reprod. 2002;21:37-44.

4. Brasil. Recomendações para a profilaxia da transmissão vertical do HIV e terapia antirretroviral em gestantes. 2010. [citado em 2017 July 12]. Disponível em: http://www.aids. gov.br/sites/default/files/consenso_ gestantes 2010 vf.pdf. 
5. Santos RCS, Souza MJA. HIV na gestação. Estação Científica UNIFAP. 2012;2:11-24.

6. Brasil. Mito vs realidade: sobre a resposta brasileira à epidemia de HIV e AIDS em 2016. 2016. [citado em 2017 July 12]. Disponível em: http://abiaids.org.br/wp-content/ uploads/2016/07/Mito-vs-Realidade_ HIV-e-AIDS_BRASIL2016.pdf.

7. Brasil. Ministério da Saúde. Boletim epidemiológico HIV/Aids 2015. Brasília; 2015. [citado em 2017 July 12]. Disponível em: http://www.aids. gov.br/publicacao/2015/boletimepidemiologico-aids-e-dst-2015.

8. Federação Brasileira de Ginecologia e Obstetrícia (FEBRASGO). Ficha clínica de pré-natal. 2017. [citado em 2017 July 12]. Disponível em: https:// pt.scribd.com/doc/316660626/FichaClinica-Pre-Natal-FEBRASGO.

9. Brasil. Ministério da Saúde. Manual técnico para diagnóstico da infecção pelo HIV no Brasil. Brasília; 2013. [citado em 2017 July 12]. Disponível em: http://bvsms.saude.gov.br/ bvs/publicacoes/manual_tecnico_ diagnostico_infeccao_hiv.pdf.

10. Correio RSM, Correio MAAL, Correio CSNB, Correio YAPP. Realização da sorologia para HIV no pré-natal - conhecimento e percepção da gestante. Rev Enferm Contemp. 2015;4:12-22.

11. Brasil. Ministério da Saúde. Diretrizes nacionais para o aconselhamento em DST/ HIV/HV. Brasília; 2012. [citado em 2017 July 12]. Disponível em: http://www.aids.gov.br/sites/ default/files/anexos/page/2012/52294/ teorizacao_oficina_acs.pdf.

12. Brasil. Ministério da Saúde. Boletim Epidemiológico HIV Aids. Brasília; 2014. [citado em 2017 July 12]. Disponível em: http://www.aids. gov.br/publicacao/2014/boletimepidemiologico-aids-e-dst-2014_final_ pdf_15565.pdf.
13. Brasil. Ministério da Saúde. Vigilância do HIV no Brasil: novas diretrizes. Brasília; 2002. [citado em 2017 July 12]. Disponível em: http://bvsms. saude.gov.br/bvs/publicacoes/162vig_ hiv_005.pdf.

14. Brasil. Ministério da Saúde. Boletim Epidemiológico HIV Aids. Brasília; 2016. [citado em 2017 July 12]. Disponível em: http:// www.aids.gov.br/sites/default/files/ anexos/publicacao/2016/59291/ boletim_2016_1_pdf_16375.pdf.

15. Brasil. Ministério da Saúde. Manual de rotinas para assistência a adolescentes vivendo com HIV/ Aids. Brasília; 2006. [citado em 2017 July 12]. Disponível em: http://bvsms.saude.gov.br/bvs/ publicacoes/10001021667.pdf.

16. Brasil. Ministério da Saúde. Indicadores e dados básicos do HIVI Aids dos municípios brasileiros. Brasília; 2017. [citado em 2017 July 12]. Disponível em: http://svs.aids.gov. br/aids/. 